\title{
Planned Activity Repeat Duration
}

National Cancer Institute

\section{Source}

National Cancer Institute. Planned Activity Repeat Duration. NCI Thesaurus. Code C94000.

The period of time over which the planned activity is repeated. 